\title{
Alleviation of genotoxic effects of cyclophosphamide using encapsulation into liposomes in the absence or presence of vitamin C
}

\author{
Amany A. Tohamy ${ }^{1}$, Amira A. Abdel Azeem², Medhat W. Shafaa ${ }^{3,4}$ and Wafaa S. Mahmoud ${ }^{1}$ \\ ${ }^{1}$ Zoology and Entomology Department, Faculty of Science, Helwan University, Cairo, Egypt \\ ${ }^{2}$ Genetics Department, Research Institute of Ophthalmology, Giza, Egypt \\ ${ }^{3}$ Physics Department, Faculty of Science, Helwan University, Cairo, Egypt \\ ${ }^{4}$ Medical Physics Department, Faculty of Medicine, Jazan University, Saudia Arabia
}

\begin{abstract}
Cyclophosphamide (CP) is a widely used anticancer and immunosuppressant that induces oxidative stress. To ameliorate the side effects resulted from $\mathrm{CP}$ treatment, liposomes were tested as an efficient drug delivery system with or without vitamin $\mathrm{C}$ as an antioxidant. $\mathrm{CP}$ resulted in clastogenic and cytotoxic effects that significantly increased for the total chromosomal aberrations as well as the numerical ones in the CP group (150.8 and 6, respectively) than the control group (6.6 and 0.0 ) as mean values at $p<0.05$. Micronucleus assay showed a significant increased micronucleated polychromatic erythrocytes percentage $($ MNPCEs $\%=11.7 \%$ ) and a significant decrease of polychromatic to normochromatic erythrocytes ratio (0.551) when compared to the group treated with liposomised $\mathrm{CP}$ and vitamin $\mathrm{C}(3.44 \% ; 0.795$, respectively) at $p<0.05$. Also, the total glutathione S-transferase activity as a body antioxidant enzyme was decreased from 52.2 in the control to 16.09 $\mathrm{nmol} / \mathrm{min} / \mathrm{mg}$ protein in CP group at $p<0.05$, while the highly significant amelioration results were observed in the liposomised vitamin $\mathrm{C}$ and $\mathrm{CP}$ group $(40.88 \mathrm{nmol} / \mathrm{min} / \mathrm{mg}$ protein). Our findings support the potential use of $\mathrm{CP}$ in a liposomal formulation doped with vitamin $\mathrm{C}$ to diminish the potential side effects of the agent.
\end{abstract}

Key words: Liposomes - Cyclophosphamide - Vitamin C - Oxidative stress - Chromosomal aberrations - Micronucleus assay - Glutathione S-transferase

\begin{abstract}
Abbreviations: CP, cyclophosphamide; GST, glutathione S-transferase; MN micronuclei; MNCPE\%, micronucleated polychromatic erythrocytes percentage; NCEs, normochromatic erythrocytes; PCEs, polychromatic erythrocytes.
\end{abstract}

\section{Introduction}

Cyclophosphamide (CP), a commonly used chemotherapeutic drug, is also well known mutagen and clastogen (Mohn and Ellenberger 1976). It is an alkylating antineoplastic agent, producing the highly active carbonium ion, which reacts with the extremely electron-rich centers of nucleic acids and proteins. Also, it induces generation of free radicals or reactive oxygen species (ROS) in vivo as well. Free radicals due to their high chemical reactivity induce cellular damage

Correspondence to: Medhat W. Shafaa, Physics Department, Faculty of Science, Helwan University, Cairo, Egypt

E-mail: medhatwi@hotmail.com in a number of ways (Bendich 1990). The most deleterious effects of free radicals include DNA damage, which can lead to a number of pathological conditions, including cancer (Richter et al. 1988).

Liposomes are self-assembling vesicles with an inner aqueous compartment surrounded by a lipid bilayer, which consists of naturally occurring phospholipids as main component (Chithrani et al. 2010; Drulis-Kawa and Dorotkiewicz-Jach 2010). Lipophilic and amphiphilic drugs can be incorporated into the liposomal bilayers whereas hydrophilic drugs can be incorporated into the inner aqueous compartment. Thus, the systemic environment does not recognize the free anticancer drug. The key to the clinical use of liposomal anticancer is to reduce systemic toxicity, which may 
ultimately depend on achieving high encapsulation efficiency and prolonged retention at tumor sites (Chang et al. 2010; Zant-Przeworska et al. 2010).

Vitamin C (L-ascorbic acid) is a bio-antimutagen (Vijayalaxmi and Venu 1999). It prevents genetic damage caused by toxicants through several mechanisms and acts mainly by interfering with free radical generation and the formation of toxic metabolites.

The present study was undertaken to evaluate the chemoprotective efficacy of liposomes doped with vitamin $\mathrm{C}$ against $\mathrm{CP}$-induced genotoxicity in male albino mice.

\section{Materials and Methods}

\section{Chemicals}

High purity L- $\alpha$-dipalmitoyl phosphatidyl choline (DPPC; 99\% pure) was purchased from Lipoid KG (Ludwigshafen, Germany), Trizma buffer was purchased from Sigma chemicals (Steinheim, Germany). Cyclophosphamide drug was purchased from Asta (Germany). Vitamin C was obtained from Sigma (USA). Chloroform was purchased from BDH chemical Ltd. (Poole, Dorset, UK; Aristar grade), Colchicine (El Nasr Pharmaceutical Chemicals Co., Egypt), Fetal calf Serum (FCS) was obtained from Sigma Chemical Co. (St. Louis, USA). All chemicals were of research grade. Solutions were prepared in de-ionized ultra pure water.

\section{Liposome preparation}

Cyclophosphamide (molar ratio $7: 2$ ) was used to prepare neutral multilamellar vesicles (MLVs) using the method of Kim et al. (1985). Briefly, $10 \mathrm{mg}$ of DPPC and $1 \mathrm{mg}$ of the drug powder at molar ratio $7: 2$ in the absence or presence of $1.37 \mathrm{mg}$ of vitamin C (at molar ratio of $4: 7$ to DPPC) were transferred to $50 \mathrm{ml}$ round bottom flask. Then $15 \mathrm{ml}$ of chloroform was added, and the flask was shaken until all lipids dissolved in the chloroform. The solvent was evaporated under vacuum using rotary evaporator until a thin dry film of lipid was formed. The flask was then left under vacuum for $12 \mathrm{~h}$ to ensure the evaporation of all traces of chloroform. $10 \mathrm{ml}$ of buffer $(10 \mathrm{mM}$ Trizma at $\mathrm{pH}=7)$ was then added to the flask which was flashed through with nitrogen stream and immediately stoppered. The flask is mechanically shaken for $1 \mathrm{~h}$ at temperature of $45^{\circ} \mathrm{C}$. The suspension was then centrifuged at $8000 \mathrm{rpm}$ for $20 \mathrm{~min}$ and the supernatant was discarded. The liposomes were then re-suspended in $10 \mathrm{ml}$ buffer solution. Control liposomes were prepared following the same classical methods as before using only aliquots of 10 mg of DPPC. The concentration of free cyclophosphamide/ $\mathrm{ml}$ of buffer calculated to be $1 \mathrm{mg} / \mathrm{ml}$.

\section{Animal groups and treatment schedule}

Eight to ten weeks old male albino Swiss mice weighing 20-25 g obtained from Research Institute of Ophthalmology (Giza, Egypt), were used in this study. They were provided with sterile food and water and observed daily for general conditions and activity levels.

The animals were divided into the following groups as 10 mice in each:

1) control group, mice with no drug treatment,

2) $\mathrm{CP}$ group, mice were given a single i.p. injection of $\mathrm{CP}$ as a single dose containing $40 \mathrm{mg} / \mathrm{kg}$ body weight (BW) as described by Vijayalaxmi and Venu (1999), 24 h before sacrificing,

3) $\mathrm{CP}$ in combination with vitamin $\mathrm{C}$ group, mice were given a single dose of vitamin C $30 \mathrm{mg} / \mathrm{kg}$ BW orally (Vijayalaxmi and Venu 1999), followed by administration of CP as a single dose $40 \mathrm{mg} / \mathrm{kg} \mathrm{BW}$ (i.p.) $24 \mathrm{~h}$ before sacrificing,

4) liposomised CP group, mice were injected with CP encapsulated into liposomes as a single dose $40 \mathrm{mg} / \mathrm{kg}$ BW (i.p.), $24 \mathrm{~h}$ before sacrificing,

5) liposomised vitamin $\mathrm{C}$ with $\mathrm{CP}$, mice in this group were injected with liposomes containing vitamin $\mathrm{C}$ and $\mathrm{CP}$ as a single dose i.p., $24 \mathrm{~h}$ before sacrificing.

\section{Cytogenetic methods}

Five mice of each group were cervically dislocated for chromosomal aberrations scoring while the other five were used for detection of formation of micronuclei $(\mathrm{MN})$ after completion of different experimental treatments schedule.

Chromosomal preparations for scoring both structural and numerical aberrations from bone marrow cells of mice that injected by colchicine $1 \mathrm{mg} / \mathrm{kg} 24 \mathrm{~h}$ before sacrificing (to stop the cell cycle at the metaphase) were based on the technique used by Yosida and Amans (1965) with some modifications. Fifty metaphase spreads per animal were examined microscopically for both structural and numerical chromosomal aberrations; only cells with well spread chromosomes were selected for scoring and some were photographed. The mitotic index (M.I.) was computed as the ratio of the dividing cells to the total examined cells $\times 100$. To calculate M.I., 1000 cells per animal were counted.

\section{Micronucleus assay}

Preparation of MN slides was arranged according to Trzos et al. (1978) method with some fixation and staining modifications. The number of normochromatic erythrocytes (NCEs) was counted in the same fields of the recorded polychromatic erythrocytes (PCEs) and incidence of MN was counted. The percentage of micronucleated polychromatic erythrocytes 


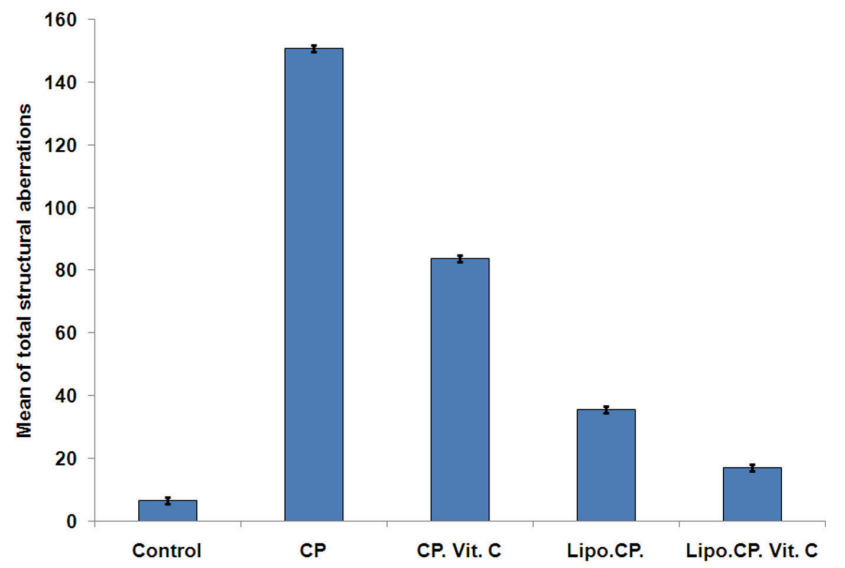

Figure 1. Changes in the total structural chromosomal aberrations among different groups

(MNPCEs\%) was calculated and the PCEs/NCEs ratio was detected.

\section{Estimation of glutathione S-transferase (GST)}

Liver has been taken from groups of mice that haven't been injected by colchicine prior to sacrificing for the measurement of GST. The part of the liver was weighed and homogenized to give $50 \%(\mathrm{w} / \mathrm{v})$ homogenate in ice-cold medium containing $50 \mathrm{mM}$ Tris- $\mathrm{HCl}$ and $300 \mathrm{mM}$ sucrose (Tsakiris et al. 2004). The homogenate was centrifuged at $3000 \mathrm{rpm}$ for $10 \mathrm{~min}$ in cooling centrifuge at $4^{\circ} \mathrm{C}$. The supernatant (10\%) was used for determinations of GST. The biodiagnostic GST Assay Kit was used to measure the total GST activity (cytosolic and microsomal) by measuring the conjugation of 1-chloro-2,4-dinitrobenzene with reduced glutathione. The conjugation is accompanied by an increase in absorbance at $340 \mathrm{~nm}$. The rate of increase is directly proportional to the GST activity in the sample (Habig et al. 1974).

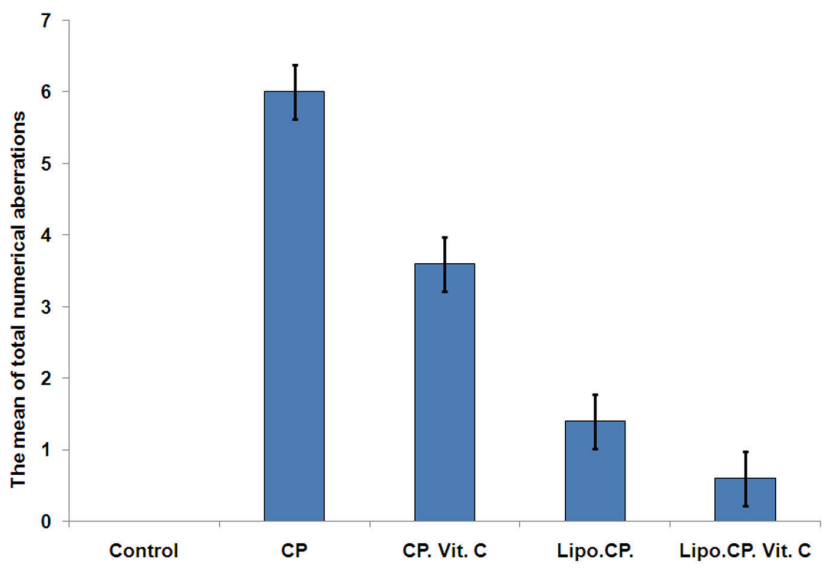

Figure 2. Changes in the total numerical chromosomal aberrations among different groups

\section{Statistical analysis}

One way analysis of variance (ANOVA) was used for multiple comparisons between all groups.

\section{Results}

The data summarized in Table 1 displayed the effect of different treatments on the bone marrow including the chromosomal aberrations, micronuclei formation and on the activities of GST antioxidant enzyme.

\section{Chromosomal aberrations results}

The chromosomal aberration assay used to detect the different kinds of chromosomal abnormalities structural as well as numerical. Figures 1 and 2 shows the changes in the total number of structural and numerical chromosomal aber-

Table 1. The effect of different treatments on the bone marrow cells including the chromosomal aberrations, micronuclei formation and on the activities of glutathione S-transferase

\begin{tabular}{lcccccc}
\hline Group & TSA & TNA & MI & P/N ratio & MNPCEs (\%) & $\begin{array}{c}\text { GST activity } \\
(\mathrm{nmol} / \mathrm{min} / \mathrm{mg} \text { protein) }\end{array}$ \\
\hline Control & $6.6 \pm 0.5143^{\mathrm{bcde}}$ & - & $16.60 \pm 0.8944^{\mathrm{bcd}}$ & $0.972 \pm 0.0156^{\mathrm{bcde}}$ & $2.18 \pm 0.239^{\mathrm{bcde}}$ & $52.2 \pm 3.178^{\mathrm{bcde}}$ \\
CP & $150.8 \pm 1.3633^{\text {acde }}$ & $6 \pm 0.707$ & $7.6 \pm 0.8944^{\text {ade }}$ & $0.551 \pm 0.0101^{\text {acde }}$ & $11.7 \pm 0.784^{\text {acde }}$ & $16.09 \pm 1.039^{\text {acde }}$ \\
CP+vitamin C & $83.8 \pm 1.534^{\text {abde }}$ & $3.6 \pm 0.42$ & $9 \pm 1.000^{\mathrm{ae}}$ & $0.687 \pm 0.0119^{\text {abde }}$ & $6.04 \pm 0.384^{\text {abde }}$ & $31.73 \pm 1.503^{\text {abe }}$ \\
Liposomised CP & $35.6 \pm 0.935^{\text {abc }}$ & $1.4 \pm 0.274$ & $12.2 \pm 0.8367^{\mathrm{ab}}$ & $0.712 \pm 0.0115^{\mathrm{abce}}$ & $4.7 \pm 0.225^{\mathrm{abce}}$ & $32.88 \pm 1.57^{\mathrm{abe}}$ \\
Liposomised CP+ & & & & & & \\
vitamin C & $17.2 \pm 0.7014^{\mathrm{abc}}$ & $0.6 \pm 0.497$ & $14 \pm 1.000^{\mathrm{b}}$ & $0.795 \pm 0.0058^{\mathrm{abcd}}$ & $3.44 \pm 0.37^{\mathrm{abcd}}$ & $40.88 \pm 3.755^{\mathrm{abcd}}$ \\
\hline
\end{tabular}

Data shown in the table as mean \pm SD. GST, glutathione S-transferase; MI, mitotic index; MNPCEs (\%), miconucleated polychromatic erythrocytes percentage; $\mathrm{P} / \mathrm{N}$ ratio, polychromatic/ normochromatic ratio; TSA, total structural aberrations; TNA, total numerical aberrations; ${ }^{a}$ significantly different from control group; ${ }^{b}$ significantly different from $\mathrm{CP}$ group; ${ }^{\mathrm{c}}$ significantly different from $\mathrm{CP}+\mathrm{vitamin} \mathrm{C}$ group; ${ }^{\mathrm{d}}$ significantly different from lipomomised $\mathrm{CP}$ group; ${ }^{\mathrm{e}}$ significantly different from lipomised $\mathrm{CP}+$ vitamin $\mathrm{C}$ group. 


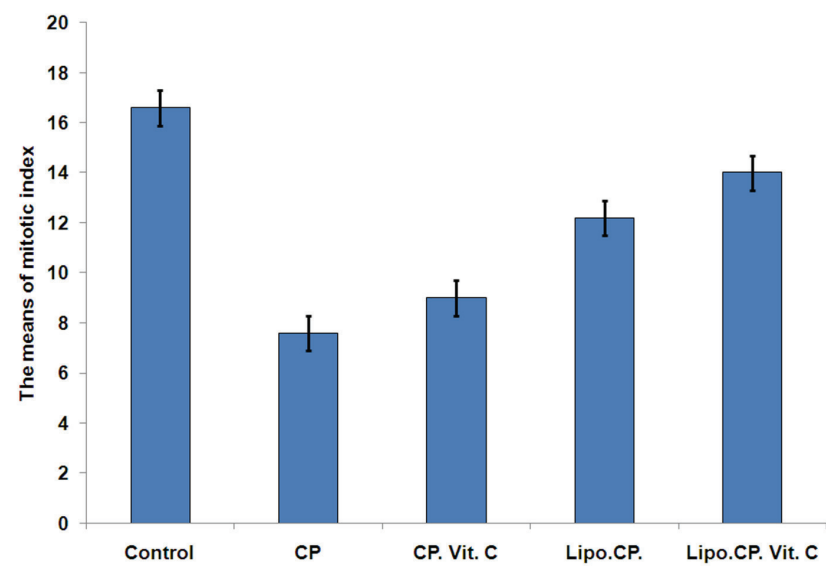

Figure 3. The variations in the mitotic indices among the different groups

rations, respectively. From these two figures, a significant change with respect to the normal control group could be easily observed in the CP-treated group $(p<0.05)$; the group of mice treated with vitamin $\mathrm{C} 24 \mathrm{~h}$ prior to $\mathrm{CP}$ injection shows a decrease in the number of aberration recorded by CP group. Also the amelioration effect of liposomes can be detected in the group treated with encapsulated CP and that with $\mathrm{CP}$ encapsulated in liposomes containing vitamin $\mathrm{C}$.

\section{M.I. results}

M.I. reveals the interaction of the drugs to the spindle apparatus. According to Figure 3, CP, vitamin C prior to CP and liposomised CP groups showed a significant decrease in M.I. when compared to the control group, while the group treated with liposomised CP with vitamin $\mathrm{C}$ showed no significant difference from that obtained in the control group.

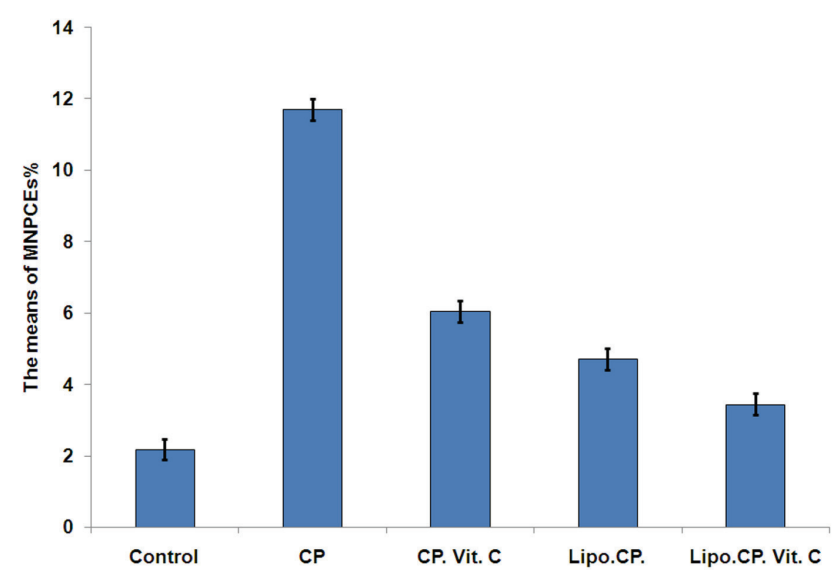

Figure 4. Micronucleated polychromatic erythrocytes percentage (MNPCEs\%) among groups

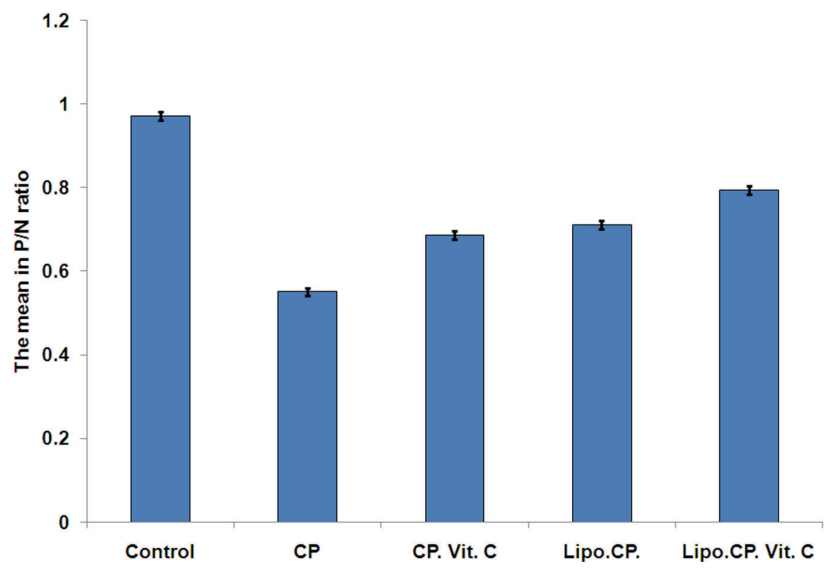

Figure 5. The changes in the polychromatic erythrocytes to normochromatic erythrocytes ratio

\section{Micronucleus assay results}

Table 1 also showed the changes in incidence of micronuclei formation, observed as a significant increase in MNPCEs\% (11.7\%) for CP group in comparison with other groups, the percentage decreased among the groups to reach $3.44 \%$ in the group treated with liposomised CP with vitamin C. The PCEs/NCEs ratio decreased in the CP group (0.551) while raised to 0.795 in the group treated with liposomes containing $\mathrm{CP}$ and vitamin C. Figures 4 and 5 summarize the percentage of MNPCEs\% and the PCEs/NCEs ratio, respectively.

\section{GST activity results}

CP group showed a significant decrease in the activity of GST as compared to the control group $(p<0.05)$. The amel-

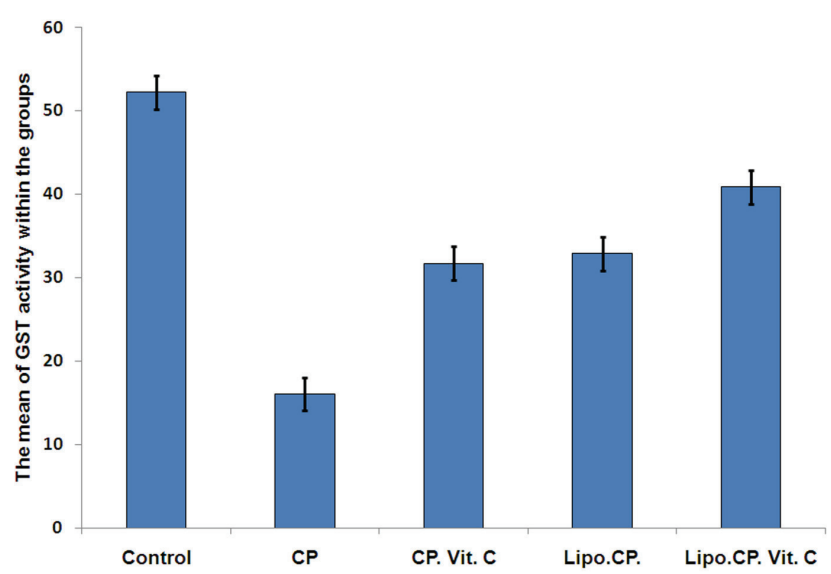

Figure 6. The differences in the means of glutathione S-transferase (GST) activity 
ioration was also observed in the group administered with vitamin C prior to CP and liposomised CP group, while the highly significant results were observed in the liposomised vitamin $\mathrm{C}$ and CP group (Table 1 and Figure 6).

\section{Discussion}

One successful approach has been to use drug carriers like liposomes to alter the pharmacokinetics and biodistribution of anticancer drugs. In general, liposome encapsulation of drugs results in (sometimes dramatic) reductions in their volume of distribution and significant increases in tumor accumulation. Liposomes, as carriers for anticancer drugs, have been shown to decrease significantly nonspecific toxicities and to deliver an increased amount of drug effectively to the tumor.

Liposomes are unique in their ability to accommodate drugs, which differ widely in physicochemical properties such as polarity, charge and size. Sites in liposomes where these drugs can localize include the liposome bilayer with its hydrophobic hydrocarbon chain core, its large polar surface, which can be neutral or charged, and the internal aqueous space. As a result, liposomes enable water-soluble and waterinsoluble materials to be used together without surfactants or other emulsifiers (Ebrahim et al. 2005).

In the present study an attempt has been made to detect the antigenotoxic activity of vitamin $\mathrm{C}$ and liposomes against CP-induced oxidative stress. CP treatment showed a significant increase in the percentage of all types of chromosomal aberrations, structural and numerical as compared to control group $(p<0.05)$. These results were consistent with previous reports (Oboh and Rocha 2007; Oboh et al. 2011) and mainly attributed to the increase in free radical production mediated by CP metabolites. Free radicals are responsible for the induction of damage to the cellular DNA that leads to the formation of chromosomal aberrations (Jagetia et al. 2003).

The group of mice treated with vitamin $\mathrm{C}$ followed by the treatment with $\mathrm{CP}$ showed a significant decrease in the range of chromosomal aberrations. Antioxidants including vitamin $\mathrm{C}$ are known to scavenge free radicals produced by $\mathrm{CP}$, thereby decreasing the degree of such effects (Jagetia et al. 2003). Moreover, treatment with CP encapsulated into liposomes and with CP encapsulated into liposomes containing vitamin $\mathrm{C}$ revealed highly significant decrease in the incidence of chromosomal aberrations.

Torchilin (2005) and Zant-Przeworska et al. (2010) reported that liposomes are considered to be advantageous candidates as drug carriers due to their ability to reduce the toxicity and/or deliver drugs to specific cells.

It has been shown that the effective delivery of a therapeutic agent to regions of pathology is largely dependent on a sufficient local concentration and an adequate amount of transport of the agent across the endothelial barrier. Liposomal drug delivery systems have been investigated for mediating the accumulation of the therapeutic agents at specific disease sites in the body (Andresen et al. 2005); so the liposomes ameliorate the toxic effects of them.

$\mathrm{MN}$ assay is considered a reliable biomarker of genotoxic exposure to both physical and chemical agents (Fenech 1993) and increase in $\mathrm{MN}$ frequency indicate exposure to clastogenic and/or aneugenic agents (Hagmar et al. 1998).

Cyclophosphamide showed a significant increase in the percentage of MNPCEs\% that agreed with many authors (Menargues et al. 1984; Mukherjee et al. 1991; Arif et al. 2009).

It has been reported that the formation of micronuclei might be a direct damage to the structure of chromosomes particularly in the pericentromeric region leading to lesions that induce chromosome breaks and to disturbances of chromosome movements during cell divisions (Goetz et al. 1975; Rothenberg 1975; Pacchierotti et al. 1983).

In the bone marrow micronucleus assay, a depression in the proportion of PCEs after treatment with CP is usually interpreted as a cytotoxic effect of this agent or its metabolite on bone marrow proliferation (Gollapudi et al. 1986). In this test, the cytotoxicity of the tested agent is routinely determined from the ratio of PCEs to NCEs which is shown to shift in favor of NCEs. This shift is attributable to the influx of peripheral blood to fill up the medullary space following bone marrow depression (Gollapudi et al. 1984). This study showed that the PCEs/NCEs ratio decreased in the CP group (0.55) while raised to 0.80 in the group treated with liposomes containing CP doped with vitamin C.

CP group also showed a highly significant decrease in the total GST activity levels in the liver than the control group. That might be due to the activity of acrolein (one of CP metabolites) that interferes with body antioxidant system; a breach in antioxidant defense system would result in proliferative production of ROS which would in turn attack hepatocyte membrane disrupting its structure and function, the result of which is a leak of these enzymes in the blood circulation (Oboh et al. 2011). In agreement with our results, Arif et al. (2009) reported a significant decrease in GST activities in the liver of mouse treated with single dose of CP. The group of animals administered with vitamin $\mathrm{C}$ orally $24 \mathrm{~h}$ prior to CP injection showed a significant increase in comparison with the level reached by CP alone (31.73vs. $16.09 \mathrm{nmol} / \mathrm{min} / \mathrm{mg}$ protein). This result might be attributed to the scavenging effect of vitamin $\mathrm{C}$ against the oxidative stress induced by CP (Donya and Aly 2003).

The data obtained from the encapsulated CP into liposomes group showed more increase in the activity of GST enzyme (32.88 $\mathrm{nmol} / \mathrm{min} / \mathrm{mg}$ protein) than that observed in the CP group; this might be due to the efficacy of liposomes in reducing the toxicity of drugs (Zant-Przeworska et al. 
2010). The activities of the total GST in mice treated with encapsulated $\mathrm{CP}$ into liposomes containing vitamin $\mathrm{C}$ were the closest to those of the control group.

\section{Conclusion}

Cyclophosphamide has toxic effects on the mice bone marrow cells where it causes severe chromosomal aberrations, induces micronuclei formation in the erythrocytes and depression in the ratio between polychromatic erythrocytes and normochromatic erythrocytes. Also it causes disruption on the activity of GST inducing an imbalanced oxidative state of the body. Thus, CP should be used under strict medical control. The role of liposomes and vitamin $\mathrm{C}$ in the amelioration of these side effects should be taken into consideration when using CP therapeutically.

\section{References}

Andresen T. L., Jensen S. S., Jorgensen K. (2005): Advanced strategies in liposomal cancer therapy: Problems and prospects of active and tumor specific drug release. Prog. Lipid. Res. 44, 68-97 http://dx.doi.org/10.1016/j.plipres.2004.12.001

Arif K., Ejaj A., Maroof A., Azmat A. K., Arun C., Fatima N., Gatoo M. A., Owais M. (2009): Protective effect of liposomal formulation of tuftsin (a naturally occurring tetrapeptide) against cyclophosphamide-induced genotoxicity and oxidative stress in mice. Indian J. Biochem. Biophys. 46, 45-52

Bendich A. (1990): Antioxidant nutrients and immune functions-introduction. Adv. Exp. Med. Biol. 262, 1-12 http://dx.doi.org/10.1007/978-1-4613-0553-8_1

Chang R. S., Kim J., Lee H. Y., Han S., Na J., Kwangmeyung K., Kwon I. C., Kim Y. B., Oh Y. (2010): Reduced dose-limiting toxicity of intraperitoneal mitoxantrone chemotherapy using cardiolipin-based anionic liposomes. NBM 6, 769-776 http://dx.doi.org/10.1016/j.nano.2010.05.003

Chithrani D. B., Dunne M., Stewart J., Allen C., Jaffray D. A. (2010) Cellular uptake and transport of gold nanoparticles incorporated in a liposomal carrier. NBM 6, 161-169 http://dx.doi.org/10.1016/j.nano.2009.04.009

Donya Souria M., Aly Kariman M. (2003): Protective effects of vitamin C, Folic acid and vitamin B12 on the mutagenic effect of methotrexate. Sci. Med. J. ESCME 15, 1-15

Drulis-Kawa Z., Dorotkiewicz-Jach A. (2010): Liposomes as delivery systems for antibiotics. Int. J. Pharm. 387, 187-198 http://dx.doi.org/10.1016/j.ijpharm.2009.11.033

Ebrahim S., Peyman G. A., Lee P. J. (2005): Application of liposomes in ophthalmology. Surv. Ophthalmol. 50, 167-182 http://dx.doi.org/10.1016/j.survophthal.2004.12.006

Fenech M. (1993): Cytokinesis-block micronucleus techniques: a detailed description of the method and its application to genotoxicity studies in human populations. Mut. Res. 161, 193-198 http://dx.doi.org/10.1016/0027-5107(86)90010-2
Goetz P., Sram R. J., Dohnalova J. (1975): Relationship between experimental results in mammals and man, I. Cytogenetic analysis of bone marrow injury induced by a single dose of cyclophosphamide. Mut. Res. 31, 247-254

Gollapudi B. B., McClintock M. L., Linscombe V. A., Shina A. K. (1984): Evaluation of the effect of food deprivation on micronucleus test results. Toxicol. Lett. 21, 353-356 http://dx.doi.org/10.1016/0378-4274(84)90096-1

Gollapudi B. B., Bruce R. J., Linscombe V. A., Watanabs P. G., Shina A. K. (1986): Effect of food and water deprivation on the parameters of the mouse bone marrow micronucleus test. Mut. Res. 173, 121-125 http://dx.doi.org/10.1016/0165-7992(86)90088-6

Habig W. H., Pabst M. J., Jakoby W. B. (1974): Glutathione S-Transferases: The first enzymatic step in mercapturic acid formation. J. Biol. Chem. 249, 7130-7139

Hagmar L., Bonassi S., Strömberg U., Mikoczy Z., Lando C., Hansteen I. L., Montagud A. H., Knudsen L., Norppa H., Reuterwall C. (1998): Cancer predictive value of cytogenetic markers used in occupational health surveillance programs: a report from an ongoing study by the European Study Group on Cytogenetic Biomarkers and Health. Mut. Res. 405, $171-178$ http://dx.doi.org/10.1016/S0027-5107(98)00134-1

Jagetia G. C., Venkatesha V. A., Reddy T. K. (2003): Naringin, a citrus flavonone, protects against radiation-induced chromosome damage in mouse bone marrow. Mutage 18, 337-343 http://dx.doi.org/10.1093/mutage/geg001

Kim S., Jacobs R. E., White S. H. (1985): Preparation of multilamellar vesicles of defined size-distribution by solvent-spherule evaporation. Biochim. Biophys. Acta 812, 793-801 http://dx.doi.org/10.1016/0005-2736(85)90274-3

Menargues M., Obach R., Valles J. M. (1984): An evaluation of the mutagenic potential of cyanamide using the micronucleus test. Mut. Res. 136, 127-129 http://dx.doi.org/10.1016/0165-1218(84)90154-X

Mohn G. R., Ellenberger J. (1976): Genetic effects of cyclophosphamide, ifosfamide and trofosfamide. Mutat. Res. 32, 331-360

Mukherjee A., Agarwal K., Aguilar M. A., Sharma A. (1991): Anticlastogenic activity of $\beta$-carotene against cyclophosphamide in mice in vivo. Mut. Res. 263, 41-46 http://dx.doi.org/10.1016/0165-7992(91)90032-Y

Oboh G., Rocha J. B. T. (2007): Polyphenols in red pepper [Capsicum annuum var. aviculare (Tepin)] and their protective effect on some pro-oxidants induced lipid peroxidation in brain and liver. Eur. Food Res. Technol. 225, 2392-2347 http://dx.doi.org/10.1007/s00217-006-0410-1

Oboh G., Akomolafe T. L., Adefegha S. A., Adetuyi A. O. (2011): Inhibition of cyclophosphamide-induced oxidative stress in rat brain by polar and non-polar extracts of Annatto (Bixa orellana) seeds. Exp. Toxicol. Pathol. 63, 257-262 http://dx.doi.org/10.1016/j.etp.2010.01.003

Pacchierotti F., Bellincampi D., Civitareale D. (1983): Cytogenetic observations, in mouse secondary spermatocytes, on numerical and structural chromosome aberrations induced by cyclophosphamide in various stages of spermatogenesis. Mut. Res. 119, 177-183 http://dx.doi.org/10.1016/0165-7992(83)90126-4 
Rathenberg R. (1975): Cytogenetic effect of cyclophosphamide on mouse spermatogonia. Humangenetik 29, 135-140 http://dx.doi.org/10.1007/BF00430350

Richter C., Park J. W., Ames B. N. (1988): Normal oxidative damage to mitochondrial and nuclear DNA is extensive. Proc. Natl. Acad. Sci. U.S.A. 85, 6465-6467 http://dx.doi.org/10.1073/pnas.85.17.6465

Torchilin V. P. (2005): Recent advances with liposomes as pharmaceutical carriers. Nat. Rev. Drug Discov. 4, 145-160 http://dx.doi.org/10.1038/nrd1632

Trzos R. J., Petzold G. L., Brunden M. N., Swenberg J. A. (1978): The evaluation of sixteen carcinogens in the rat using the micronucleus test. Mut. Res. 58, 79-86 http://dx.doi.org/10.1016/0165-1218(78)90097-6

Tsakiris S., Schulpis K. H., Marinou K., Behrakis P. (2004): Protective effect of L-cysteine and gluthathione on the modulated suckling rat brain $\mathrm{Na}+, \mathrm{K}+$-ATPase and $\mathrm{Mg} 2+-\mathrm{ATPase}$ activities induced by the in vitro galactosaemia. Pharmacol. Res. 49, 475-479 http://dx.doi.org/10.1016/j.phrs.2003.11.006

Vijayalaxmi K. K., Venu R. (1999): In vivo the anticlastogenic activity of L-ascorbic acid in mice. Mut. Res. 438, 47-51

Yosida T. H., Amano K. (1965): Autosomal polymorphism in laboratory bred and wild Norway rats, Rattus norvegicus found in Misima. Chromosoma 16, 658-667 http://dx.doi.org/10.1007/BF00285115

Zant-Przeworska E., Stasiuk M., Gubernator J., Kozubek A. (2010): Resorcinolic lipids improve the properties of sphingomyelincholesterol liposomes. Chem. Phys. Lipids 163, 648-654 http://dx.doi.org/10.1016/j.chemphyslip.2010.05.202

Received: July 23, 2011

Final version accepted: October 17, 2011 